EFFECTS OF DIPYRIDAMOLE IN COMBINATION WITH ANTICOAGULANT THERAPY ON SURVIVAL AND THROMBOEMBOLIC EVENTS IN PATIENTS WITH PROSTHETIC HEART VALVES

\section{A meta-analysis of the randomized trials}

The addition of dipyridamole, an antiplatelet agent, to conventional anticoagulant regimens has been shown to reduce the frequency of embolization after valve replacement with a mechanical prosthesis. The purpose of this meta-analysis was to reevaluate the benefit of dipyridamole by analyzing the evidence from all randomized clinical trials. Summary data were extracted from the application to the Food and Drug Administration. Six randomized clinical trials had accrued 1141 patients, of whom 582 received anticoagulant therapy alone and 559 received additional dipyridamole at dosages ranging from 225 to $400 \mathrm{mg}$ per day. The events analyzed were all thromboembolic events, both fatal and nonfatal; hemorrhagic events, both fatal and nonfatal; and the overall mortality. The combination of dipyridamole with anticoagulants reduced the risk of thromboembolic events (fatal or nonfatal) by $56 \%$ when compared with the use of anticoagulants alone $(p=\mathbf{0 . 0 0 0 1})$. The risk reduction was seen in fatal and in nonfatal thromboembolic events (risk reduction for fatal events, 64\%, $p=$ 0.008 ; for nonfatal events, $50 \%, p=\mathbf{0 . 0 0 5}$ ). The overall mortality rate was also significantly reduced by $40 \%$ in the group receiving dipyridamole $(p=$ 0.013). There was no difference between treatment groups with respect to hemorrhagic events (risk reduction, $-1 \%, p=0.94$ ). This meta-analysis supports the use of dipyridamole in this setting and warrants further trials with new antiplatelet agents. (J THORAC CARDIOVASC SuRG 1995;110:463-72)

Hubert Pouleur, MD, ${ }^{a}$ and Marc Buyse, $\mathrm{ScD},{ }^{\mathrm{b}}$ Brussels, Belgium
$E^{v e r a s}$ ven in the presence of adequate anticoagulant therapy with warfarin or similar compounds, serious thromboembolic events remain a frequent complication after valve replacement with a mechanical prosthesis. ${ }^{1-5}$ In 1971 Sullivan, Harken, and Gorlin ${ }^{6}$ were the first to show that the addition of dipyridamole, an antiplatelet agent, to the conventional anticoagulant regimen significantly reduced the frequency of embolization. Other studies that pointed toward a similar conclusion followed ${ }^{7-22}$ and dipyridamole eventually was granted approval for this indication in most countries.

More recently, however, the clinical efficacy of

From the Department of Physiology and Pharmacology and the Division of Cardiology, University of Louvain, School of Medicine, ${ }^{a}$ and the International Institute for Drug Development, ${ }^{\mathrm{b}}$ Brusseis, Belgium.

Received for publication June 16, 1994.

Accepted for publication Nov. 15, 1994.

Address for reprints: Hubert Pouleur, MD, University of Louvain, avenue Hippocrate 55/5560, B-1200 Brussels, Belgium.

Copyright 11995 by Mosby-Year Book, Inc.

$0022-5223 / 95 \$ 3.00+0 \quad \mathbf{1 2 / 1 / 6 2 4 6 9}$ dipyridamole as an antiplatelet agent has been seriously questioned. ${ }^{23}$ These criticisms, together with the publication of other trials that showed less convincing or equivocal results after valve replacement, ${ }^{24,25}$ made it important to reconsider the possible benefits of the use of dipyridamole after mechanical valve replacement, in terms of both clinical efficacy and safety. With this purpose in mind, a meta-analysis of all available data obtained under controlled conditions was done. Meta-analysis, which consists of combining evidence from several sources, may be done in several ways not all of which are equally reliable. One approach, which is often regarded as the gold standard of meta-analysis, consists of collecting individual patient data on all patients ever entered in randomized clinical trials. ${ }^{26}$ At the other extreme, a commonly used approach consists of reviewing only published reports of clinical trials and extracting information from these publications. This approach has been criticized because it may be subject to publication bias and published reports typically do not contain the data needed for the meta-analysis. ${ }^{27,28}$ We have used yet another approach, because we were able to 
Table I. Controlled trials using dipyridamole combined with anticoagulants (warfarin or similar compounds) in prevention of thromboembolic events in patients with prosthetic heart valves

\begin{tabular}{|c|c|c|c|c|c|}
\hline & Treatments & $N$ & End points & $\begin{array}{l}\text { Follow-up } \\
(m o)\end{array}$ & $\begin{array}{l}\text { Reported results or conclusions } \\
\text { as stated in the paper }\end{array}$ \\
\hline \multirow[t]{2}{*}{ Sullivan $1971^{6}$} & AVK + placebo & 84 & \multirow{2}{*}{$\begin{array}{l}\text { Thromboembolic events: } \\
\text { cerebral or peripheral } \\
\text { and myocardial infarc- } \\
\text { tions when the embo- } \\
\text { lus was proven by an } \\
\text { autopsy }\end{array}$} & \multirow[t]{2}{*}{$12^{*}$} & $\begin{array}{l}\text { Significant reduction of emboli- } \\
\text { zation in the dipyridamole } \\
\text { group }\end{array}$ \\
\hline & $\begin{array}{l}\text { AVK + dipyridamole } \\
400 \mathrm{mg} / \text { day }\end{array}$ & 79 & & & $\begin{array}{l}\text { No difference between death } \\
\text { rates }\end{array}$ \\
\hline \multirow[t]{2}{*}{ Kasahara $1977^{7}$} & AVK alone & 39 & \multirow{2}{*}{$\begin{array}{l}\text { Any thromboembolic } \\
\text { event }\end{array}$} & \multirow[t]{2}{*}{$27 \uparrow$} & \multirow{2}{*}{$\begin{array}{l}\text { Reduced incidence of thrombo- } \\
\text { embolic events and deaths in } \\
\text { dipyridamole group }\end{array}$} \\
\hline & $\begin{array}{l}\text { AVK + dipyridamole } \\
400 \mathrm{mg} / \text { day }\end{array}$ & 39 & & & \\
\hline \multirow[t]{2}{*}{ Boissel $1978{\text { (PACTE })^{24}}^{24}$} & AVK alone & 202 & \multirow{2}{*}{$\begin{array}{l}\text { Thromboembolic events } \\
\text { including myocardial } \\
\text { infarctions and deaths } \\
\text { of any cause }\end{array}$} & \multirow[t]{2}{*}{$12^{*}$} & \multirow{2}{*}{$\begin{array}{l}\text { No trend in favor of the dipyri- } \\
\text { damole-treated group }\end{array}$} \\
\hline & $\begin{array}{l}\text { AVK + dipyridamole } \\
375 \mathrm{mg} / \text { day }\end{array}$ & 183 & & & \\
\hline \multirow[t]{2}{*}{$\operatorname{Bran} 1980^{\circ}$} & AVK alone & 43 & \multirow{2}{*}{$\begin{array}{l}\text { Thromboembolic events } \\
\text { and deaths }\end{array}$} & \multirow[t]{2}{*}{$24^{*}$} & \multirow{2}{*}{$\begin{array}{l}\text { Dipyridamole reduces the inci- } \\
\text { dence of thromboembolic } \\
\text { events provided that daily } \\
\text { dosage is adequate }\end{array}$} \\
\hline & $\begin{array}{l}\text { AVK }+ \text { dipyridamole } \\
\text { up to } 5 \mathrm{mg} / \mathrm{kg} \text { per } \\
\text { day }\end{array}$ & 58 & & & \\
\hline \multirow[t]{2}{*}{ Rajah $1980^{9}$} & AVK alone & 87 & \multirow{2}{*}{$\begin{array}{l}\text { Thromboembolic events } \\
\text { and deaths }\end{array}$} & \multirow[t]{2}{*}{$30 \div$} & \multirow{2}{*}{$\begin{array}{l}\text { Dipyridamole reduces signifi- } \\
\text { cantly the incidence of } \\
\text { thromboembolic events }\end{array}$} \\
\hline & $\begin{array}{c}\text { AVK + dipyridamole } \\
225 \text { to } 400 \mathrm{mg} / \text { day }\end{array}$ & 68 & & & \\
\hline \multirow[t]{2}{*}{ Starkman $1982^{25}$} & AVK alone & 127 & \multirow{2}{*}{$\begin{array}{l}\text { Thromboembolic events } \\
\text { and deaths }\end{array}$} & \multirow[t]{2}{*}{$12^{*}$} & \multirow{2}{*}{$\begin{array}{l}\text { Inconclusive results: a larger } \\
\text { sample size would be neces- } \\
\text { sary }\end{array}$} \\
\hline & $\begin{array}{l}\text { AVK + dipyridamole } \\
375 \mathrm{mg} / \text { day }\end{array}$ & 132 & & & \\
\hline
\end{tabular}

$N$, Number of patients; $A V K$, anticoagulants.

* Fixed duration of follow-up for each patient.

$\dagger$ Mean value, follow-up extended up to 45 months.

† Mean value, range 10 to 49 months.

obtain access to the registration file that had been reviewed by the U.S. Food and Drug Administration (FDA) to grant market authorization to dipyridamole. The registration file contains much more detailed information on the clinical trials than the corresponding publications, and therefore some of our analyses are based on data that have until now remained unpublished.

\section{Methods}

Trial selection. All prospective, randomized, controlled trials that assessed the prevalence of thromboembolic events and deaths in a group treated with warfarin (or similar compound) plus dipyridamole and that compared this prevalence with that in a control group receiving the same anticoagulant therapy without dipyridamole were considered eligible for inclusion in this meta-analysis.

Noncontrolled studies and retrospective studies ${ }^{10-22}$ were not included. The trials were identified by a systematic search through the MEDLINE database and from the documentation submitted to the FDA for approval of the use of dipyridamole in the prevention of thromboembolic events in patients with prosthetic heart valves. Six trials that met the eligibility criteria were found (Table I). They included a total of 1141 patients, of whom 582 received anticoagulant therapy alone and 559 received in addition dipyridamole at dosages ranging from 225 to $400 \mathrm{mg}$ per day. The duration of follow-up is listed in Table I. In all but one trial (the PACTE trial ${ }^{24}$ ) the patients were randomized after operation. Details on the anticoagulant treatment used in each trial are provided in Table II.

Data extraction. The events analyzed were all thromboembolic events, both fatal and nonfatal; hemorrhagic events, both fatal and nonfatal; and the overall mortality. Thromboembolic events included all cerebral emboli, other arterial emboli, and myocardial infarctions and strokes. Only two deaths were classified as sudden; these sudden deaths were also considered as thromboembolic events to avoid any bias in the assessment of such events. ${ }^{29}$ Summary data were extracted from the published papers and from the documentation submitted to the FDA by two independent observers and then compared for possible discrepancies to reach a final consensus after returning to the source of data. The analysis was done on a strict intention-to-treat basis, attributing all target events to the treatment group to which the patients had been randomized whether or not the patients were known to be compliant with the treatment.

Statistical methods. The statistical analysis was done with the use of standard modifications of the MantelHaenszel stratified analysis of contingency tables. ${ }^{26}$ These methods required, in each trial, the number of events observed in the dipyridamole group $(\mathrm{O})$, the number of events that would be expected if there were no benefit 
Volume 110, Number 2

Table II. Details on the anticoagulant treatment used in the six controlled trials

\begin{tabular}{|c|c|c|c|c|}
\hline & Anticoagulant drug & Time started & Timing of evaluations & Basis for anticoagulant dosage \\
\hline Sullivan $1971^{6}$ & Warfarin & 4 days after operation & $\begin{array}{l}\text { Every } 6 \text { months by hospital } \\
\text { plus at intervals deter- } \\
\text { mined by attending phy- } \\
\text { sician }\end{array}$ & $\begin{array}{l}\text { Control prothrombin time } \\
\text { values } \times 2\end{array}$ \\
\hline Kasahara $1977^{7}$ & Warfarin & $\begin{array}{l}1 \text { or } 2 \text { days after opera- } \\
\text { tion }\end{array}$ & Every 2 weeks by hospital & $\begin{array}{c}\text { Owren thrombotest } 10 \% \text { to } \\
25 \% \text { of control values }\end{array}$ \\
\hline $\begin{array}{l}\text { Boissel } 1978 \\
\quad \text { (PACTE) }^{24}\end{array}$ & $\begin{array}{l}\text { Phenindione or } \\
\text { acenocoumarol }\end{array}$ & 7 days after operation & 1 to 3 weeks & $\begin{array}{l}\text { Quick time } 25 \% \text { to } 35 \% \text { of } \\
\text { control value }\end{array}$ \\
\hline Bran $1980^{8}$ & $\begin{array}{l}\text { Dicoumarin deriva- } \\
\text { tives }\end{array}$ & NA & NA & $\begin{array}{l}\text { Quick time or Owren throm- } \\
\text { botest (no target specified) }\end{array}$ \\
\hline Rajah $1980^{9}$ & Warfarin & $\begin{array}{l}1 \text { or } 2 \text { days after opera- } \\
\text { tion }\end{array}$ & $\begin{array}{l}\text { Every } 6 \text { weeks in the pro- } \\
\text { thrombin clinic }\end{array}$ & Prothrombin ratio $1.9-3.0$ \\
\hline Starkman $1982^{25}$ & NA & 2 weeks after operation & $\begin{array}{l}\text { Every } 3 \text { to } 4 \text { weeks by at- } \\
\text { tending physician }\end{array}$ & $\begin{array}{l}\text { Quick time } 25 \% \text { to } 35 \% \text { of } \\
\text { control }\end{array}$ \\
\hline
\end{tabular}

$N A$, Information not available.

Table III. Prevalence of events in the six controlled trials that used anticoagulants alone or in combination with dipyridamole

\begin{tabular}{|c|c|c|c|c|c|c|c|c|c|c|}
\hline \multirow[b]{2}{*}{ Trial } & \multicolumn{2}{|c|}{$\begin{array}{c}\text { Thromboembolic } \\
\text { events }\end{array}$} & \multicolumn{2}{|c|}{$\begin{array}{c}\text { Nonfatal } \\
\text { thromboembolic events }\end{array}$} & \multicolumn{2}{|c|}{$\begin{array}{c}\text { Fatal thromboembolic } \\
\text { events }\end{array}$} & \multicolumn{2}{|c|}{ Deaths } & \multicolumn{2}{|c|}{ Hemorrhagic events } \\
\hline & $A V K+D I P$ & $A V K$ & $A V K+D I P$ & $A V K$ & $A V K+D I P$ & $A V K$ & $A V K+D I P$ & $A V K$ & $A V K+D I P$ & $A V K$ \\
\hline Sullivan $^{6}$ & $6 / 79$ & $14 / 84$ & $2 / 79$ & $8 / 84$ & $4 / 79$ & $6 / 84$ & $11 / 79$ & $10 / 84$ & $4 / 79$ & $5 / 84$ \\
\hline Kasahara $^{7}$ & $2 / 39$ & $8 / 39$ & $2 / 39$ & $2 / 39$ & $0 / 39$ & $6 / 39$ & $3 / 39$ & $7 / 39$ & $1 / 39$ & $1 / 39$ \\
\hline Boissel $^{24}$ & $9 / 183$ & $20 / 202$ & $8 / 183$ & $17 / 202$ & $1 / 183$ & $3 / 202$ & $10 / 183$ & $35 / 202$ & $62 / 183$ & $69 / 202$ \\
\hline $\operatorname{Bran}^{8}$ & $6 / 58$ & $8 / 43$ & $5 / 58$ & $5 / 43$ & $1 / 58$ & $3 / 43$ & $4 / 58$ & $6 / 43$ & NA & NA \\
\hline Rajah $^{9}$ & $3 / 68$ & $11 / 87$ & $2 / 68$ & $8 / 87$ & $1 / 68$ & $3 / 87$ & $7 / 68$ & $6 / 87$ & $4 / 68$ & $7 / 87$ \\
\hline Starkman $^{25}$ & $5 / 132$ & $8 / 127$ & $5 / 132$ & $8 / 127$ & $0 / 132$ & $0 / 127$ & $5 / 132$ & $3 / 127$ & $9 / 132$ & $5 / 127$ \\
\hline Total & $31 / 559$ & $69 / 582$ & $24 / 559$ & $48 / 582$ & $7 / 559$ & $21 / 582$ & $40 / 559$ & $67 / 582$ & $80 / 501$ & $87 / 539$ \\
\hline
\end{tabular}

$A V K$, Anticoagulants; $D I P$, dipyridamole; $N A$, information not available.

of dipyridamole $(\mathrm{E})$, and the variance of this number of events (V). From $\mathrm{O}, \mathrm{E}$, and $\mathrm{V}$ one could calculate the odds ratio of the event in the dipyridamole group as compared with that in the control group, the confidence limits of this odds ratio, and a standardized deviate to test its statistical significance (test for treatment effect). The same calculations were done for the overall odds ratio by replacing $\mathrm{O}, \mathrm{E}$, and $\mathrm{V}$ by their summation over all trials. ${ }^{30}$ Individual odds ratios were represented graphically by a solid square, the surface of which is proportional to the corresponding variance $\mathrm{V}$, that is, to the information content of that trial. Trials with many events have a large information content, and their odds ratio is therefore represented by a large square; conversely, trials with few events have a small information content, and their odds ratio is represented by a small square. For each end point, the relative benefit of dipyridamole was expressed as a risk reduction and its associated confidence interval (CI). An odds ratio equal to $\mathrm{OR}$ was taken as indicating a risk reduction of 1 -OR. For each end point, a $\chi^{2}$ statistic was also calculated to test any apparent differences between the results of the individual trials (test for heterogeneity). All CIs were calculated with use of a probability coverage of $95 \%$. All p values were calculated with two-tailed tests. All calculations were done with the SAS software (SAS Institute, Cary, N.C.).

\section{Results}

Meta-analysis. Summary data extracted from each trial to perform the analyses are listed in Table III and the results of the meta-analyses are displayed in Figs. 1 to 5.

The combination of dipyridamole with anticoagulants reduced the risk of thromboembolic events (fatal or nonfatal) by $56 \%$ when compared with the risk with anticoagulants alone $(95 \%$ CI of the risk reduction, $33 \%$ to $71 \% ; \mathrm{Z}=3.85 ; p=0.0001$ ) (Fig. 1).

The overall mortality rate was also significantly reduced by $40 \%$ in the group receiving dipyridamole (95\% CI of the risk reduction, $10 \%$ to $60 \% ; \mathrm{Z}=$ 2.47; $p=0.013$ ) (Fig. 2). For this end point, however, the test for heterogeneity showed that 


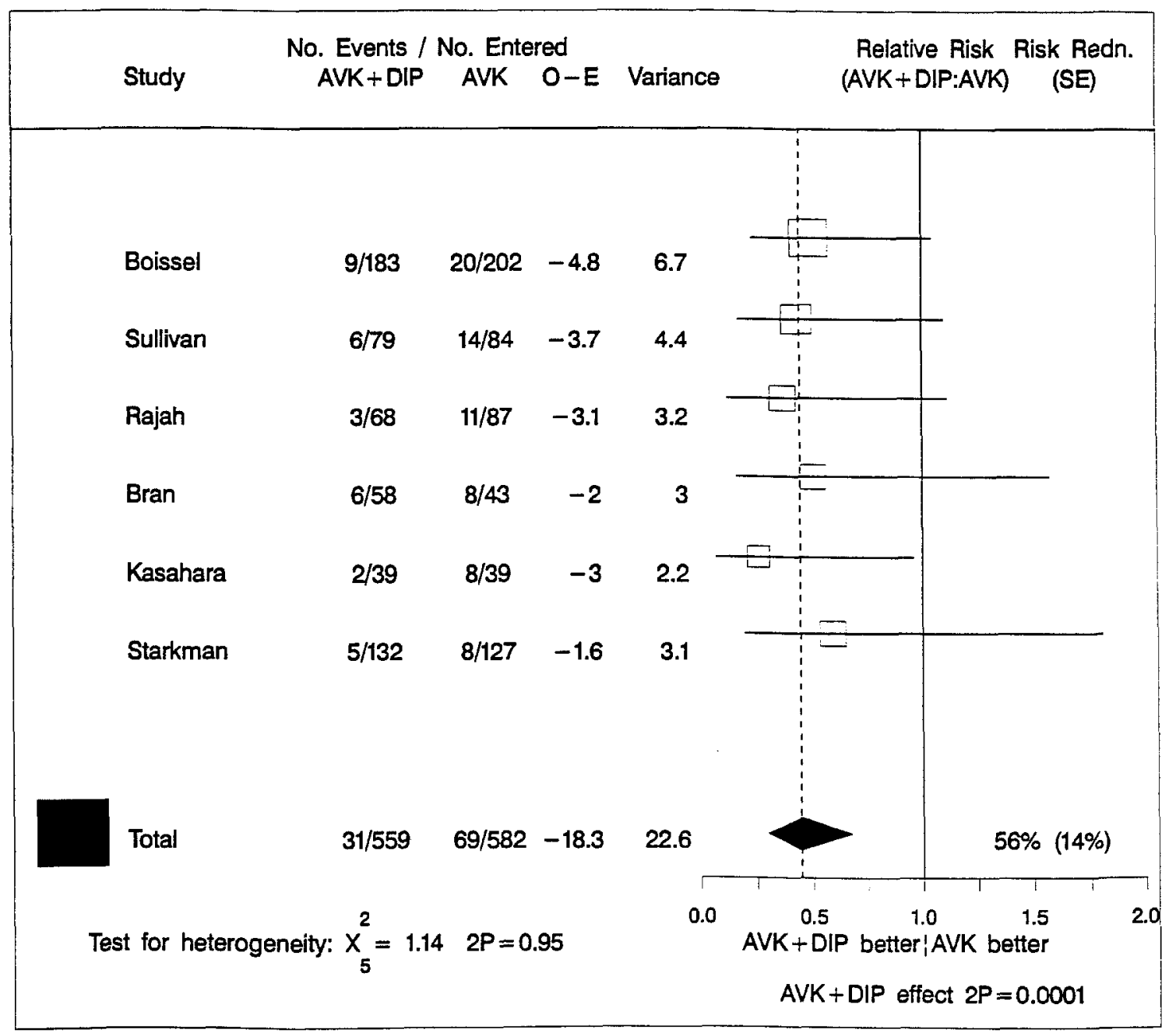

Fig. 1. Meta-analysis of all thromboembolic events, whether fatal or not, in six controlled trials that used warfarin or similar compounds $(A V K)$ alone or in combination with dipyridamole $(D I P)$. $O, E$, Frequency of observed and expected events; Risk Redn, risk reduction; $S E$, standard error of risk reduction.

significant differences existed between individual trials $(p=0.046)$. Fig. 2 shows that most of the benefit in terms of overall mortality was a result of the findings of a single trial. ${ }^{24}$ In this trial, patients were randomized before operation and all perioperative deaths were included in the overall mortality in keeping with the intention-to-treat analysis. As it turns out, there was a major imbalance in perioperative deaths between the two randomized groups in this trial (dipyridamole, 1; control group, 12), and this imbalance largely contributed to the observed difference between the dipyridamole and control groups. However, there was still a difference in favor of dipyridamole in this trial even after exclusion of the perioperative deaths (dipyridamole, 9; control group, 23).

The benefit of dipyridamole on mortality was confirmed when fatal and nonfatal thromboembolic events were considered separately (Table III). In the dipyridamole group, there was, indeed, a $64 \%$ reduction in the risk of death caused by thromboembolic events $(95 \% \mathrm{CI}$ of the risk reduction, $23 \%$ to $83 \% ; \mathrm{Z}=2.63 ; p=0.008)$ without noticeable heterogeneity between trials (Fig. 3 ). When the two sudden deaths were excluded from this analysis (both of which had occurred in the control group), there was still a $61 \%$ risk reduction in favor of dipyridamole $(p=0.019)$. There was also a $50 \%$ 


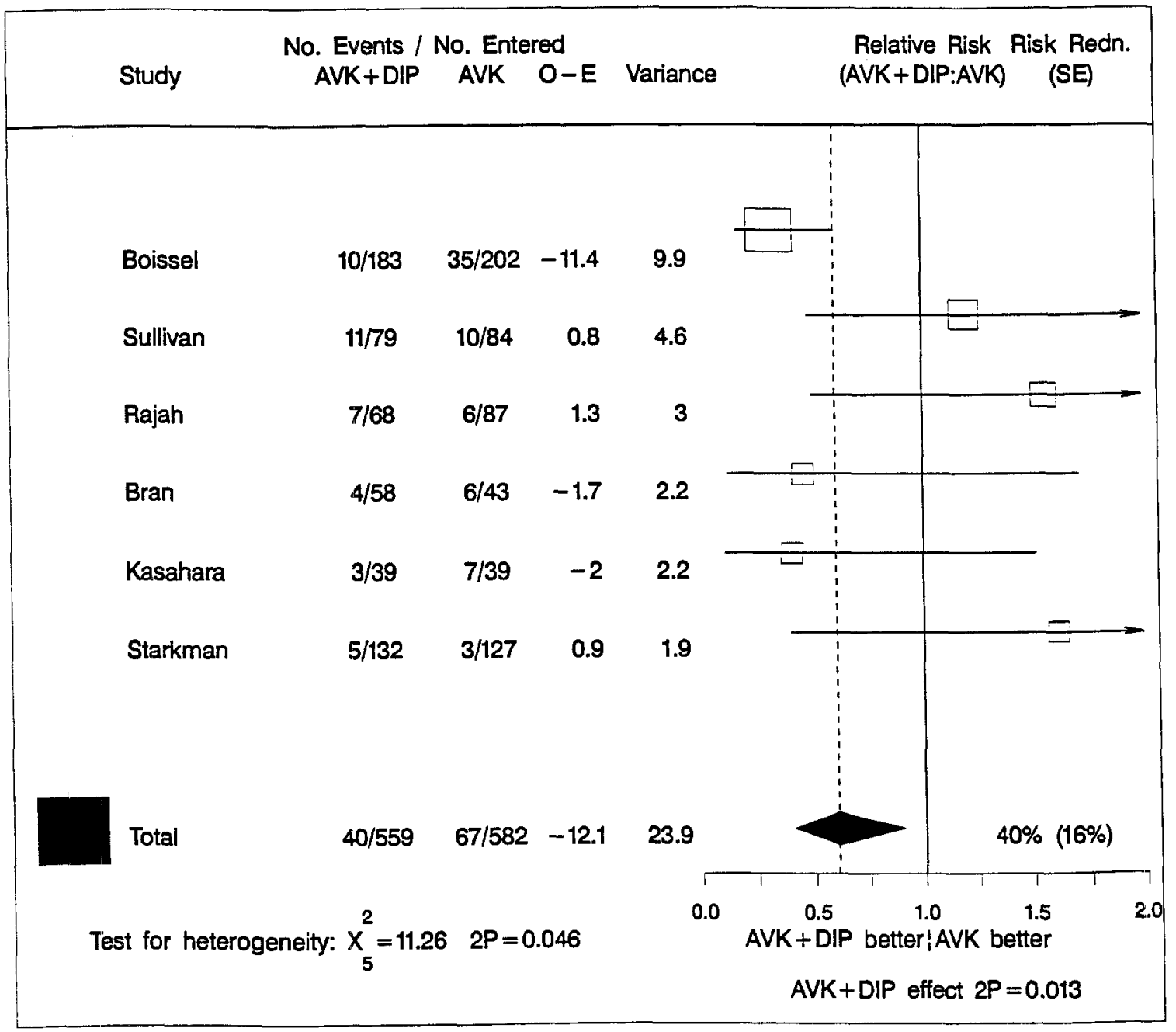

Fig. 2. Meta-analysis of total mortality (see legend of Fig. 1 for details).

reduction in the risk of nonfatal thromboembolic events $(95 \% \mathrm{CI}$ of the risk reduction, $19 \%$ to $69 \%$; $\mathrm{Z}=2.80 ; p=0.005$ ) (Fig. 4).

The occurrence of hemorrhagic events, whether fatal or not, did not differ between both treatment groups (Table III). The relative risk was almost identical in both treatment groups $(95 \% \mathrm{CI}$ of the risk reduction, $-45 \%$ to $29 \% ; \mathrm{Z}=0.005 ; p=0.94$ ) (Fig. 5). There were too few fatal hemorrhages to do meaningful comparisons between the two groups (among the four trials with data on fatal hemorrhages, four deaths were reported in the dipyridamole group versus five in the anticoagulants-alone group).

\section{Discussion}

Patients with prosthetic cardiac valves are permanently at high risk of thromboembolic complica- tions. The pathologic events that lead to the thrombus formation at the valve level are complex and involve both platelet aggregation and direct activation of coagulation factors. ${ }^{1,4,5}$ Platelet activation may be sufficient to trigger the clotting system but there is also evidence that prosthetic materials can directly activate coagulation factor XII and induce thrombus formation independently of the platelets. ${ }^{4}$ Although anticoagulants such as warfarin act downstream of factor XII in the coagulation cascade, the incidence of thromboembolic complications remains high in patients who receive anticoagulants alone, which led to clinical trials to explore the benefit of the combination of anticoagulants with antiplatelet drugs.

The present meta-analysis clearly supports the recommendations on the use of dipyridamole in this indication $^{1,4,5}$ and also casts some new light on the 


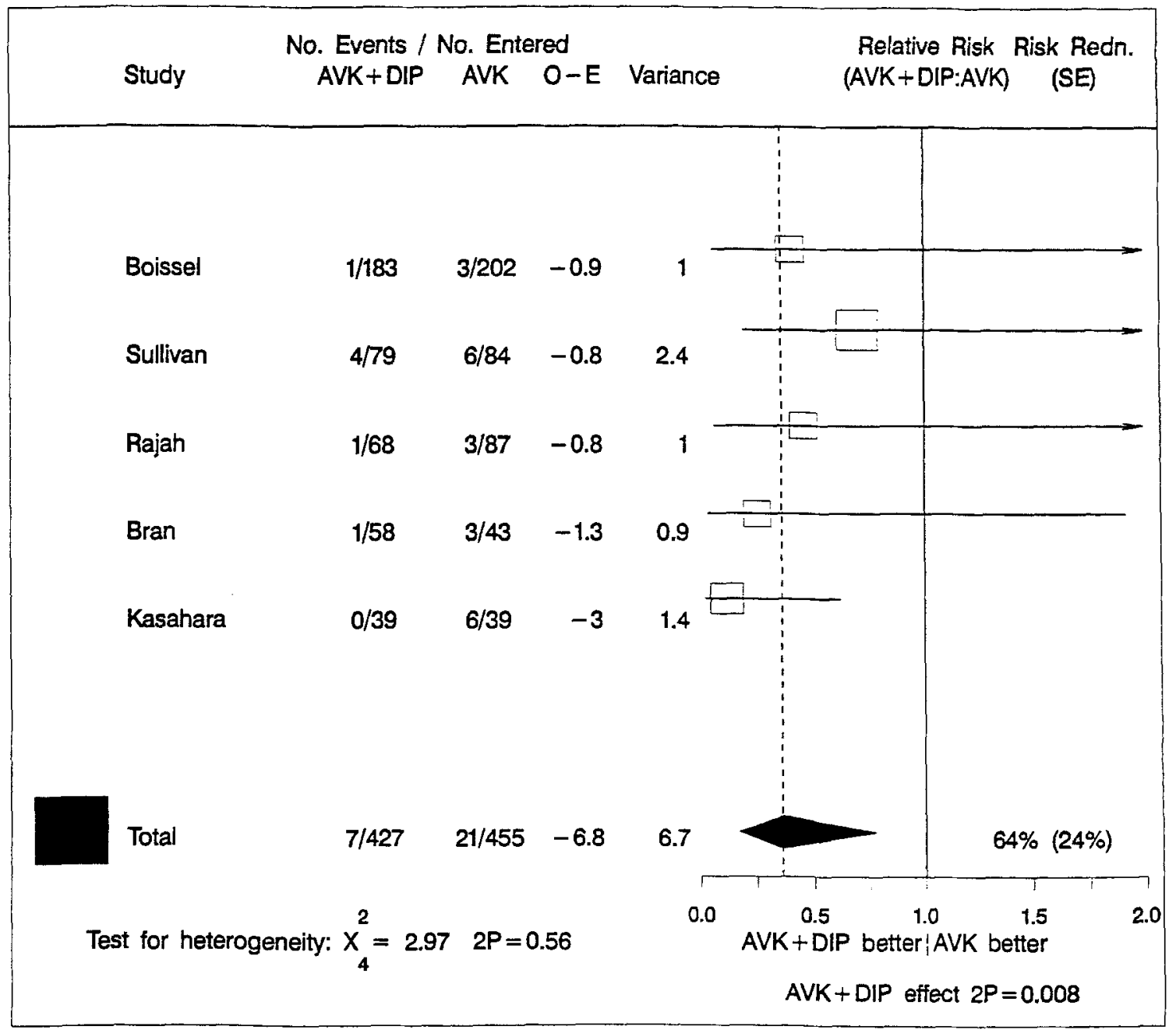

Fig. 3. Meta-analysis of all fatal thromboembolic events, including sudden deaths (see legend of Fig. 1 for details).

magnitude of the benefit and on the safety of the therapy. Obviously, meta-analyses have their limitations, but so have most statistical analyses done in published reports of individual clinical trials. In this respect, two features of the present meta-analysis deserve special emphasis. First, the data on which the calculations were based came from the registration file submitted to the United States FDA, rather than solely from the published reports of the individual trials. Even though it would have been preferable to have information on the times to the target events for all individual patients, the analysis done on overall proportions of events yields a valid and powerful test of treatment benefit when, as is the case here, these events are relatively infrequent. ${ }^{30}$ Second, the data were analyzed with an intentionto-treat approach, so that all patients were kept in the group allocated by randomization regardless of outcome or treatment actually received. This had not always been done in the published papers, which may have seriously biased some of the reported results. The intention-to-treat approach is preferable to an analysis of properly treated patients because it is in general more conservative and is therefore less likely to conclude wrongly to a treatment benefit. In the present series of trials, the intention-to-treat approach may appear particularly problematic for the PACTE trial, ${ }^{24}$ in which patients were randomized before operation and several days before the therapy was started. In this trial, because more patients died perioperatively in the control group than in the dipyridamole group, the intentionto-treat approach may have resulted in an overestimation of the benefit of dipyridamole on overall 


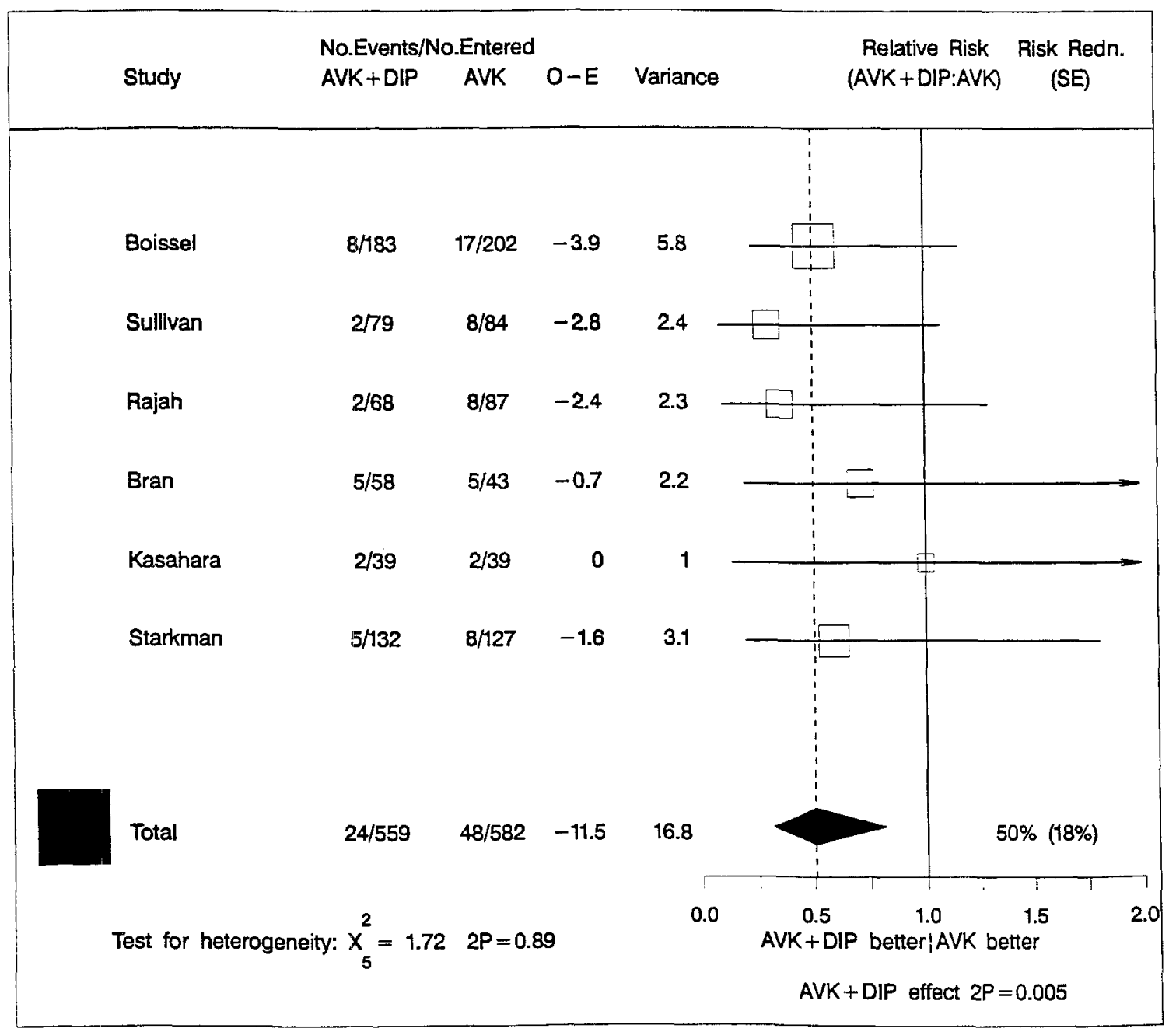

Fig. 4. Meta-analysis of nonfatal thromboembolic events (see legend of Fig. 1 for details).

mortality. Nevertheless, this problem did not affect the analysis of fatal thromboembolic events, which did not include perioperative events, and the analysis showed a major benefit of dipyridamole. It is noteworthy that in this meta-analysis there was also a clear risk reduction in favor of dipyridamole that remained significant regardless of the inclusion or elimination of the sudden deaths as thromboembolic events.

Some concern could be expressed about the possibility that thromboembolic events were defined and assessed differently in the trials considered. However, it should be stressed that the statistical techniques used in the present meta-analysis only compare patients receiving anticoagulants alone with those receiving combined therapy in the same trial. Hence the estimate of the benefit of dipyridamole is valid within each trial. Differences in design between trials would only be important if the study designs were known to have a major influence on the benefit of adding dipyridamole to anticoagulants therapy. We have no evidence that this is indeed the case for the differences in design observed between the six trials, such as the end points used (Table I), the anticoagulant therapy (Table II), or the type and position of the prosthetic cardiac valve (data not shown). Even if there were underlying differences in the therapeutic benefit of dipyridamole between various subgroups of patients, the number of trials and of observations would not permit their reliable detection. ${ }^{31}$

The consistency of the results across all end points 


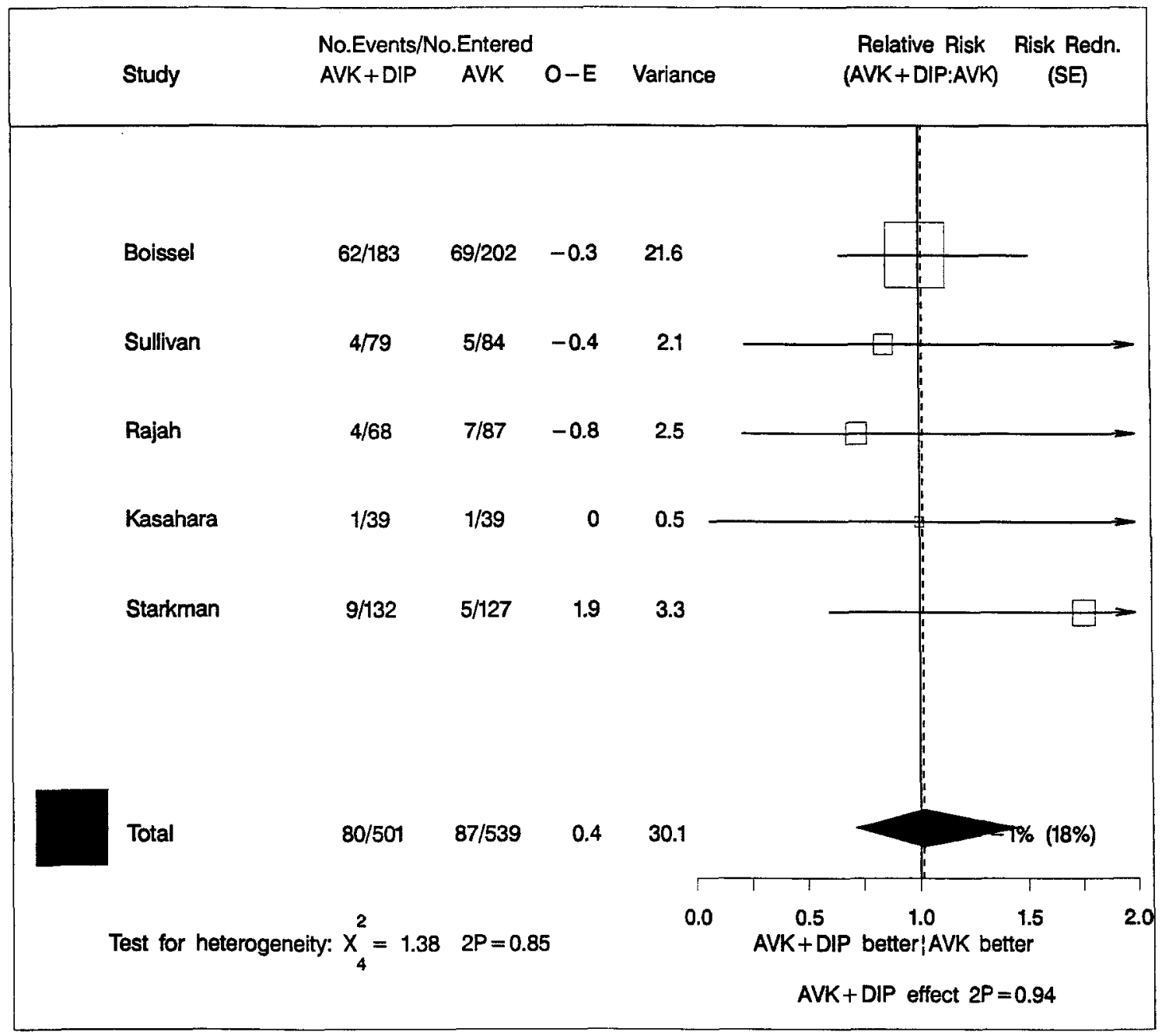

Fig. 5. Meta-analysis of all hemorrhagic events, whether fatal or not (see legend of Fig. 1 for details).

examined, together with the positive results reported in other trials ${ }^{10-22}$ that did not meet our criteria for inclusion in the meta-analysis, strongly supports the efficacy of the combination therapy. With the use of dipyridamole there appeared to be a $56 \%$ risk reduction in the prevalence of thromboembolic events, which is larger than the reductions reported with aspirin. ${ }^{11,32}$ Furthermore, the combination of warfarin with aspirin resulted in an increased prevalence of gastrointestinal tract and intracerebral bleeding, ${ }^{11}$ even in trials that used low doses of aspirin. ${ }^{32}$

Dipyridamole has a long safety record showing that if its use is sometimes limited by unpleasant side effects, it is devoid of serious adverse effects such as neutropenia, which may occur with other antiplatelet agents. ${ }^{33}, 34$ It therefore appears to be a drug of choice to be combined with anticoagulants in patients with mechanical prostheses. One major safety concern, just as for aspirin, is the occurrence of hemorrhagic events, some of which may be fatal. Our meta-analysis showed no indication of a difference in hemorrhagic events between the combined therapy and the use of anticoagulants alone, whether all events were considered or only fatal ones. If anything, the combined therapy showed fewer hemorrhagic events, but the difference was far from statistical significance. The overall mortality difference in favor of dipyridamole, together with the absence of any noticeable increase in bleeding complications, provides compelling evidence that the net effect of dipyridamole is beneficial.

One may wonder whether the combined therapy is cost effective as compared with monotherapy with anticoagulants alone. Overall, the prevalence of 
thromboembolic events was reduced from $11.86 \%$ with anticoagulant alone to $5.55 \%$ with the combined therapy. If 1000 patients were treated, this would result in 119 and 56 events, respectively. These events included cerebral emboli, peripheral emboli, valve thrombi, and myocardial infarction. It was unclear from the publications whether all nonfatal peripheral emboli and valve thrombi required hospitalizations. Nevertheless, patients with mechanical prostheses and a suspected or obvious thromboembolic complication are usually hospitalized, at least for a complete check-up. The duration of hospital stay for stroke or myocardial infarction ranges in our institution from 1 to more than 60 days, with a mean of $17 \pm 5$ days (standard error of the mean). On the basis of these figures, the additional cost imposed by the administration of dipyridamole may well be more than compensated by the savings made by the prevention of hospitalization costs and the additional cost of outpatient treatment after a thromboembolic event. The longterm costs related to a permanent neurologic deficit (nursing, physiotherapy, and so on) further tip the financial balance in favor of dipyridamole therapy. Although a more detailed cost analysis would be warranted, as would a comparison between dipyridamole and low-dose aspirin therapy, it is likely that the drastic reduction in serious thromboembolic events, which require hospitalization and may lead to permanent disability, may make the treatment cost effective and clinically worthwhile.

An unavoidable limitation of meta-analyses is that, by relying on past information, they may reach conclusions that are correct but no longer relevant at the time of their publication because of technologic or therapeutic progress. More than two decades have passed since the work of Sullivan, Harken, and Gorlin, ${ }^{6}$ and during that period many technical improvements have been made to heart prostheses. Nevertheless, even in 1995, thromboembolic complications still probably remain the most common adverse events in patients with mechanical valve prostheses. This entirely justifies not only revisiting dipyridamole efficacy but also considering alternative therapeutic approaches. Indeed, even combined therapy with dipyridamole is unable to completely prevent thromboembolic complications. Still, the positive results obtained with a combined therapy support the hypothesis that more powerful antiplatelet agents that do not interfere with anticoagulant therapy could perhaps be even more effective than dipyridamole. New powerful antiplatelet agents, such as thromboxane $\mathrm{A}_{2}$ antagonists, are now being explored in the clinical setting and the results of this meta-analysis confirm that these compounds may be beneficial in patients with mechanical heart valves.

We thank Dr. Jean-Marie Bertrand-Hardy from Boehringer Ingelheim Belgium for his help in providing the source documents needed for the study and for his useful comments. The criticisms made by three anonymous reviewers led to substantial improvements in the paper. The secretarial help of Ms. Isabelle Mottard is also gratefully acknowledged.

\section{REFERENCES}

1. Chesebro JH, Adams PC, Fuster V. Antithrombotic therapy in patients with valvular heart disease and prosthetic heart valves. J Am Coll Cardiol 1986; 8(Suppl):41B-56B.

2. Edmunds LH. Thromboembolic complications of current cardiac valvular prosthesis. Ann Thorac Surg 1982;34:96-104.

3. Thorburn CW, Morgan JJ, Shanaban MX, Chang VP. Long-term results of tricuspid valve replacement and the problem of prosthetic valve thrombosis. Am J Cardiol 1983;51:1128-32.

4. Stein B, Fuster V, Halperin J, Chesebro JH. Antithrombotic therapy in cardiac disease: an emerging approach based on pathogenesis and risk. Circulation 1989;80:1501-13.

5. Stein PD, Kantrowitz A. Antithrombotic therapy in mechanical and biological prosthetic heart valves and saphenous vein bypass grafts. Chest 1989;95: 1075-175.

6. Sullivan JM, Harken DE, Gorlin R. Pharmacologic control of thromboembolic complications of cardiacvalve replacement. N Engl J Med 1971;284:1391-4.

7. Kasahara T. Clinical effect of dipyridamole ingestion after prosthetic heart valve replacement: especially on the blood coagulation system. J Jpn Assoc Thorac Surg 1977;25:1007-21.

8. Bran M, Capel P, Messin R. Reduction of platelet activity in patients with prosthetic heart valves. Rev Med Brux 1980;1:71-5.

9. Rajah SM, Sreegnaran N, Watson DA. A prospective trial of dipyridamole and warfarin in heart valve patients [Abstract]. Acta Therapeutica 1980;6:54.

10. Altman R, Rouvier J, Gurfinkel E, et al. Comparison of two levels of anticoagulant therapy in patients with substitute heart valves. J THORAC CARDIOVASC SURG 1991;101:427-31.

11. Chesebro JH, Fuster V, Elveback LR, et al. Trial of combined warfarin plus dipyridamole or aspirin therapy in prosthetic heart valve replacement: danger of aspirin compared with dipyridamole. Am $\mathbf{J}$ Cardiol 1983;51:1537-41. 
12. Czer LSC, Chaux A, Matloff JM, De Robertis MA, Gray RJ. Ten-year experience with the St. Jude Medical valve for primary valve replacement. J THORaC Cardiovasc Surg 1990;100:44-55.

13. El Makhlouf A, Friedli B, Oberhansli I, Rouge JC, Faidutie R. Prosthetic heart valve replacement in children. J Thorac Cardiovasc Surg 1987;93:80-5.

14. Hartz RS, LoCicero J III, Kucich V, et al. Comparative study of warfarin versus antiplatelet therapy in patients with a St. Jude Medical valve in the aortic position. J Thorac Cardiovasc Surg 1986;92:684-90.

15. Kawazoe K, Fujita T, Manabe H. Dipyridamole combined with anticoagulant in prevention of early postoperative thromboembolism after cardiac valve replacement. Thromb Res 1990;60(Suppl):27-33.

16. McGrath LB, Gonzales-Lavin L, Eldredge WJ, Colombi M, Restrepo D. Thromboembolic and other events following valve replacement in a pediatric population treated with antiplatelet agents. Ann Thorac Surg 1987;43:285-7.

17. Mok CK, Boey J, Wang R, et al. Warfarin versus dipyridamole-aspirin and pentoxifylline-aspirin for the prevention of prosthetic heart valve thromboembolism: a prospective randomized clinical trial. Circulation 1985;72:1059-63.

18. Nair CK, Mohiuddin SM, Hilleman DE, et al. Tenyear results with the St. Jude Medical prosthesis. Am J Cardiol 1990;65:217-25.

19. Rao PS, Solymar L, Mardini MK, Fawzy ME, Guin G. Anticoagulant therapy in children with prosthetic valves. Ann Thorac Surg 1989;47:589-92.

20. Ribeiro PA, Al Zaibag MA, Idris M, et al. Antiplatelet drugs and the incidence of thromboembolic complications of the St. Jude medical aortic prosthesis in patients with rheumatic heart disease. J THORAC Cardiovasc Surg 1986;91:92-8.

21. Serra AJS, McNicholas KW, Olivier HFJ, Boe SL, Lemole GM. The choice of anticoagulation in pediatric patients with the St. Jude Medical valve prostheses. J Cardiovasc Surg 1987;28:588-91.

22. Verrier ED, Tranbaugh RF, Soifer SJ, Yee ES, Turley $\mathrm{K}$, Ebert PA. Aspirin anticoagulation in children with mechanical aortic valves. J THORAC CARDIOVASC SURG 1986;92:1013-20.
23. Fitzgerald GA. Dipyridamole. N Engl J Med 1987; 316:1247-57.

24. Boissel JP. P.A.C.T.E: prévention des accidents thrombo-emboliques systémiques chez les porteurs de prothèses valvulaires artificielles-essai coopératif contrôlé du dipyridamole. Coeur 1978;9:915-69.

25. Starkman C, Estampes B, Vernant P, Acar J. Prévention des accidents thrombo-emboliques systémiques chez les patients porteurs de prothèses valvulaires artificielles: essai prospectif de l'association anti-vitamines-K-dipyridamole. Arch Mal Coeur 1982;75:85-8.

26. Antiplatelet Trialists' Collaboration. Secondary prevention of vascular disease by prolonged antiplatelet treatment. BMJ 1988;296:320-31.

27. Begg CB, Berlin JA. Publication bias: a problem in interpreting medical data. J R Stat Soc A 1988;151: 419-63.

28. Stewart LA, Parmar MKB. Meta-analysis of the literature or of individual patient data: is there a difference? Lancet 1993;341:418-22.

29. The Dutch TIA Trial Study Group. A comparison of two doses of aspirin ( $30 \mathrm{mg}$ vs $283 \mathrm{mg}$ a day) in patients after a transient ischemic attack or minor ischemic stroke. N Engl J Med 1991;325:1261-6.

30. Buyse M, Ryan LM. Issues of efficiency in combining proportions of deaths from several clinical trials. Stat Med 1987;6:565-76.

31. Buyse M. Analysis of clinical trial outcomes: some comments on subgroup analyses. Control Clin Trials 1989;10:187S-94S.

32. Turpie AGG, Gent M, Laupacis A, et al. A comparison of aspirin with placebo in patients treated with warfarin after heart-valve replacement. $\mathrm{N}$ Engl J Med 1993;329:524-9.

33. Haynes RB, Sandler RS, Larson EB, Pater JL, Yatsu FM. A critical appraisal of ticlopidine, a new antiplatelet agent: effectiveness and clinical indications for prophylaxis of atherosclerotic events. Arch Intern Med 1992;152:1376-80.

34. Hass WK, Easton JD, Adams HP, et al. A randomized trial comparing ticlopidine hydrochloride with aspirin for the prevention of stroke in high-risk patients. N Engl J Med 1989;321:501-7. 